\title{
The phylogenetic position of Gallinuloides Eastman (Aves: Galli- formes) from the Tertiary of North America
}

\author{
GARETH J. DYKE \\ Department of Zoology, University College Dublin, Belfield Dublin 4, Ireland ; gareth.dyke@ucd.ie
}

\begin{abstract}
I have extended a recent phylogenetic analysis of morphological characters for galliform birds (pheasants, grouse, partridges and allies) to investigate the placement of the enigmatic fossil Gallinuloides wyomingensis Eastman. This analysis shows that, contrary to most previous interpretations, the fossil Gallinuloides is a basal member of the 'phasianoid' assemblage within Galliformes - not basal within the order as has been previously proposed. This conclusion is supported by several clear osteological features preserved on the holotype and only currently described specimen of this enigmatic fossil bird. Resolving the evolutionary relationships of Gallinuloides is of importance because this fossil taxon has proved a key player in debates regarding the timing of the diversification of all modern birds (Neornithes)_Gallinuloides has been used as both an internal and external fossil calibration point for molecular clock hypotheses dealing with the pattern and timing of the neornithine evolutionary radiation.
\end{abstract}

Key words: Galliformes, Phasianidae, Gallinuloides, phylogeny, molecular clocks, Neornithes

\section{Introduction}

The pattern and extent in time of the evolutionary radiation of modern birds (=Neornithes) is one of the most disputed topics in current evolutionary biology. Debates have revolved around the timing of the appearance of the neornithine clades and the extent to which they had diversified by the terminal Cretaceous-Tertiary (K-T) extinction event. In addition to direct interpretations of the fossil record of modern birds (Olson 1985; Feduccia 1995; Dyke 2001), one approach that has been widely employed to estimate the timing of clade divergences has been the use of molecular clock models. However, such clock methods for timing divergences depend on the known fossil record to provide calibration points for nodes within cladograms - the accuracy of phylogenetic placements for fossils are therefore paramount to the accuracy of such methods (Dyke 2001; van Tuinen \& Hedges 2003). 